\title{
Influence of mechanical grinding on lithium insertion and extraction properties of iron silicide/silicon
} composites

\author{
Hiroyuki Usui ${ }^{1,2}$, Kazuma Nouno ${ }^{1,2}$, Yuya Takemoto ${ }^{1,2}$, Kengo Nakada ${ }^{3}$, Akira Ishii ${ }^{3}$, \\ Hiroki Sakaguchi ${ }^{1,2, *}$
}

${ }^{1}$ Department of Chemistry and Biotechnology, Graduate School of Engineering, Tottori University, 4-101 Minami, Koyama-cho, Tottori 680-8552, Japan

${ }^{2}$ Center for Research on Green Sustainable Chemistry, Tottori University, 4-101 Minami, Koyama-cho, Tottori 680-8552, Japan

${ }^{3}$ Department of Applied Mathematics and Physics, Tottori University, 4-101 Minami, Koyama-cho, Tottori 680-8552, Japan

*Corresponding author. Tel./Fax: +81-857-31-5265; e-mail: sakaguch@ @ chem.tottori-u.ac.jp

Keywords: FeSi2/Si composite; Ferrosilicon; Li-ion battery anode; Mechanical grinding; Gas-deposition

\begin{abstract}
We prepared composite electrodes of iron silicide/Si by using mechanical grinding for mixtures of ferrosilicon and $\mathrm{Si}$ followed by gas-deposition, and investigated their electrochemical properties as Li-ion battery anode. With increasing the mechanical grinding time, the phase transformation from FeSi to $\mathrm{FeSi}_{2}$ took place more significantly, and the composite electrode showed better cycle stabilities. There was no remarkable difference in mechanical properties and electronic conductivity between FeSi and $\mathrm{FeSi}_{2}$. On the other hand, the $\mathrm{FeSi}_{2}$ exhibited about three times larger capacities in comparison with the FeSi electrode. In addition, a result of our first principle calculation indicates that Li ion can diffuse more easily in $\mathrm{FeSi}_{2}$ lattice than in FeSi lattice. It is suggested that the better cyclability of the composite electrodes was attributed to the moderate reactivity of $\mathrm{FeSi}_{2}$ with $\mathrm{Li}$ and the smooth $\mathrm{Li}$-ion diffusion in it.
\end{abstract}




\section{Introduction}

Li-ion battery has been extensively studied in these days not only for portable electronic devices but also for electric vehicles. In particular, much larger energy density is required for the electric vehicles. Based on this requirement, Si has attracted much attention as a high-capacity anode material in the next-generation Li-ion battery. It can accommodate 3.75 Li ions per $\mathrm{Si}$ atom at room temperature [1-5]. This accommodation leads to a theoretical capacity of about $3580 \mathrm{~mA} \mathrm{~h} \mathrm{~g}$, which is approximately ten times higher than the theoretical capacity of a graphite anode in practical use. On the other hand, Si has critical disadvantages of a low electronic conductivity, a slow kinetics of Li-ion diffusion, and significant volume changes during Li-insertion and Li-extraction. The volume changes are a very serious problem as anode material because those cause a huge mechanical stress and a loss of electrical contact between active material and current collector. The electrode performance, consequently, drastically degrades with increasing charge-discharge cycles. Many researchers have studied various composite electrodes consisted of elemental $\mathrm{Si}$ and other active materials compensating for the silicon's disadvantages.

Since about 2003, the authors have intensively investigated various anode materials of intermetallic compounds [6-9], Si-based composites [10-20], and elemental Si [21-23]. As a part of these results, it has been revealed that silicon's high capacity can be effectively exerted for a long term charge-discharge cycle by a combination of elemental $\mathrm{Si}$ and suitable other active materials. We have reported that four kinds of properties are mainly required for the active materials as follows [10-20]:

1. Mechanical properties suitable for relaxation of the stress from $\mathrm{Si}$

2. High electronic conductivity

3. Moderate reactivity with $\mathrm{Li}^{+}$

4. High thermodynamic stability

As for the fourth factor, transition metal silicides are promising as the active materials because they have generally high thermodynamic stabilities. The authors have succeeded in improving anode performances of composite electrodes consisted of elemental $\mathrm{Si}$ and rare-earth metal silicides such as $\mathrm{LaSi} / \mathrm{Si}$ [11], 
mischmetal silicide $\left(\mathrm{MmSi}_{2}\right) / \mathrm{Si}$ [15], and $\mathrm{Gd}-\mathrm{Si} / \mathrm{Si}$ [25]. On the other hand, we have investigated $\mathrm{Li}$-insertion/extraction properties for composite electrodes of $\mathrm{Si}$ and base metal silicide such as $\mathrm{FeSi} / \mathrm{Si}$ [15,24], $\mathrm{NiSi}_{2} / \mathrm{Si}$ [24], and $\mathrm{VSi}_{2} / \mathrm{Si}$ [15,24]. From the viewpoint of abundance and cost, it is very important to utilize iron silicides for an electrode material of large size Li-ion battery for electric vehicles and stationary batteries.

Ferrosilicon $(\mathrm{Fe}-\mathrm{Si})$ is one of several ferroalloys used for desulfurization and deoxidation from molten steel in a steel process. The $F e-S i$ is less expensive than metal grade $\mathrm{Si}$ ( $4 \mathrm{~N}$ purity) because it is widely used in great quantities in steel industry. It consists of mostly $\mathrm{FeSi}_{2}$ which shows charge-discharge capacities of about several ten $\mathrm{mA} \mathrm{h} \mathrm{g}^{-1}$. The capacities are considered an appropriate reactivity with $\mathrm{Li}^{+}$as the third factor. Moreover, $\mathrm{FeSi}_{2}$ has a more ductile property, a higher electrical conductivity, and a higher thermodynamic stability compared with elemental Si. As a preceding study, Ai et al. reported that $\mathrm{FeSi} 2 / \mathrm{Si} / \mathrm{C}$ nanocomposites were synthesized by a ball-milling method, and that the nanocomposite electrodes showed an excellent capacity retention of $92 \%$ at the 200th charge-discharge cycle in a conventional organic electrolyte [26]. On the other hand, Choi and Kim et al. prepared a sputtered $\mathrm{FeSi}_{2.7}\left(\mathrm{FeSi}_{2} / \mathrm{Si}\right.$ composite) thin-film delivering a good retention of $92 \%$ at the 100th cycle even in an ionic liquid electrolyte [27]. They have purchased, however, commercial source materials of $\mathrm{Fe}$ and $\mathrm{Si}$ for the $\mathrm{FeSi}_{2}$ synthesis though the composites of $\mathrm{FeSi}_{2}$ and $\mathrm{Si}$ were found to be excellent anode active materials. Therefore, it is expected that $\mathrm{Fe}-\mathrm{Si}$ becomes a promising candidate to be combined with $\mathrm{Si}$ as a low-cost anode material. In this study, we applied $\mathrm{Fe}-\mathrm{Si}$ to Si-based composite electrodes and investigated their electrochemical properties as Li-ion battery anode.

\section{Experimental}

As an active material, $\mathrm{Fe}-\mathrm{Si}$ and $\mathrm{Si}$ powders $\left(\operatorname{Silgrain}^{\circledR}\right.$ e-Si, Elkem AS) were used. The average particle sizes of the $\mathrm{Fe}-\mathrm{Si}$ and $\mathrm{Si}$ powders were approximately $60 \mu \mathrm{m}$ and $10 \mu \mathrm{m}$, respectively. A mechanical grinding (MG) was performed for a mixture of the $\mathrm{Fe}-\mathrm{Si}$ and $\mathrm{Si}$ powders to obtain a 
composite active material of $\mathrm{Fe}-\mathrm{Si}$ and $\mathrm{Si}(\mathrm{Fe}-\mathrm{Si} / \mathrm{Si})$. The mixture of the $\mathrm{Fe}-\mathrm{Si}$ and $\mathrm{Si}$ powders was put in a zirconia vessel together with balls so that the weight ratios of $\mathrm{Fe}-\mathrm{Si}$ :Si were 70:30, 50:50, and 30:70. The weight ratio of the balls to the active materials was 15:1. The vessel used was sealed to keep an atmosphere of dry argon gas. The MG was carried out by using a high-energy planetary ball mill (P-6, Fritsch) for 10, 20, and 30 hours with a rotation speed of $380 \mathrm{rpm}$ at room temperature, resulting in a formation of $\mathrm{Fe}-\mathrm{Si} / \mathrm{Si}$ composite powders. The particle sizes of the composite powders were measured by a using a laser diffraction particle size analyzer (SALD-2300, Shimadzu Co. Ltd.). The typical sizes of primary particles were confirmed to be about $0.1 \mu \mathrm{m}$. The crystal structure of the powders was confirmed by using X-ray diffraction (XRD, Ultima IV, Rigaku). A reference breaking strength of the powders was measured by a uniaxial compression test using a dynamic ultra-micro hardness tester (DUH-211S, Shimadzu Co. Ltd.). In this study, the reference breaking strength was defined as an applied pressure when a compressed particle of the powder showed $10 \%$ deformation compared with its original size. The electrical resistivity was measured for the powders under a uniaxial press of $55 \mathrm{MPa}$ using a two probes method.

Thick-film electrodes of $\mathrm{Fe}-\mathrm{Si} / \mathrm{Si}$ composites were prepared by a gas-deposition (GD) method [9,23]. This method is a unique process in which thick films thicker than $1 \mu \mathrm{m}$ consisting of various metal, alloy, and oxide powders can be easily formed by a single deposition without any binder. Procedures and conditions of thick-film electrode preparation have been described in our previous reports [9-23]. In this study, we prepared $\mathrm{Fe}$-Si/Si composite film electrodes by using a nozzle with $0.5 \mathrm{~mm}$ in diameter, an $\mathrm{Ar}$ carrier gas with a purity of $99.99 \%$ under a differential pressure of $7.0 \times 10^{5} \mathrm{~Pa}$, and a current collector of $\mathrm{Cu}$ foil substrate with $20 \mu \mathrm{m}$ in thickness. The active material weights in the electrodes were typically kept within the range of $46-79 \mu \mathrm{g}$.

Li-insertion/extraction properties of the composite electrodes were evaluated in a beaker-type there-electrode cell. We assembled the composite electrodes as a working electrode, Li metal sheets (Rare Metallic, 99.90\%) as counter and reference electrodes, and $\mathrm{LiClO}_{4}$ dissolved in propylene 
carbonate (PC; $\mathrm{C}_{4} \mathrm{H}_{6} \mathrm{O}_{3}$, Kishida Chemical Co., Ltd.) at a concentration of $1 \mathrm{M}$ as the electrolyte. Galvanostatic charge-discharge tests were carried out using an electrochemical measurement system (HJ-1001 SM8A, Hokuto Denko Co., Ltd.) at $303 \mathrm{~K}$ with potential ranges of $0.005-2.000 \mathrm{~V}$ vs. $\mathrm{Li} / \mathrm{Li}^{+}$. The current densities were set to be $1.0 \mathrm{~A} \mathrm{~g}^{-1}$, corresponding to current rates of $0.40-0.93 C$.

To investigate behavior of Li-ion migration in iron silicides, we performed first principle calculations based on density functional theory (DFT) using projector augmented wave (PAW) method as implemented in the Vienna Ab Initio Simulation Package (VASP) [28,29]. The local density approximation (LDA) was also used as the term exchange correlation with a cutoff energy of $350 \mathrm{eV}$ and all calculations performed nonmagnetically. The Brillouin zone sampling was done via a $(6 \times 6 \times 6) k$-point mesh within Gamma point centered mesh scheme. Structural relaxation was carried out to determine all atomic positions after $\mathrm{Li}$ was inserted into crystal lattices of $\mathrm{FeSi}_{2}$ and $\mathrm{FeSi}$. We calculated a formation energy $E_{\mathrm{f}}$ for $\mathrm{Li}$-inserted $\mathrm{FeSi} 2$ in a super cell consisted of six unit cells as an interstitial solid solution $\left(\mathrm{Li}_{0.17} \mathrm{FeSi}_{2}\right)$ from a total energy $E_{\text {total. }}$ The $E_{\mathrm{f}}$ of $\mathrm{Li}_{0.17} \mathrm{FeSi}_{2}$ was defined by

$$
E_{\mathrm{f}}\left(\mathrm{Li}_{0.17} \mathrm{FeSi}_{2}\right)=E_{\text {total }}\left(\mathrm{Li}_{0.17} \mathrm{FeSi}_{2}\right)-0.17 E_{\text {total }}(\mathrm{Li})-E_{\text {total }}\left(\mathrm{FeSi}_{2}\right) .
$$

As for $\mathrm{Li}$-inserted $\mathrm{FeSi}, E_{\mathrm{f}}$ of $\mathrm{Li}_{0.06} \mathrm{FeSi}$ in a super cell consisted of four unit cells was calculated by equation of

$$
E_{\mathrm{f}}\left(\mathrm{Li}_{0.06} \mathrm{FeSi}\right)=E_{\text {total }}\left(\mathrm{Li}_{0.06} \mathrm{FeSi}\right)-0.06 E_{\text {total }}(\mathrm{Li})-E_{\text {total }}(\mathrm{FeSi})
$$

To evaluate Li migration in crystal structure, we calculated the formation energies in migration pathway between the most stable interstitial sites of $\mathrm{Li}$. As an energy barrier for the migration, changes in formation energies of $\mathrm{Li}$-inserted $\mathrm{FeSi} 2$ were investigated when Li migrates between adjacent stable sites.

\section{Results and discussion}

Figure 1 shows XRD patterns of $\mathrm{Fe}-\mathrm{Si}$ powder as received. We can recognize diffraction peaks of not only $\mathrm{FeSi}_{2}$ (Inorganic Crystal Structure Database, ICSD No.01-073-1843) but also FeSi (ICSD 
No.01-079-0619). It was confirmed that $\mathrm{Fe}-\mathrm{Si}$ powder consists of a mixture of $\mathrm{FeSi}_{2}$ and $\mathrm{FeSi}$. A thick-film electrode using $\mathrm{Fe}-\mathrm{Si}$ alone, prepared for a preliminary experiment, showed low discharge capacities less than $20 \mathrm{~mA} \mathrm{~h} \mathrm{~g}^{-1}$ and a very stable cyclability as we expected. Although as-received $\mathrm{Fe}-\mathrm{Si}$ alone is not suitable for anode material, we expected high capacity and stable cyclability by compounding $\mathrm{Fe}-\mathrm{Si}$ with elemental $\mathrm{Si}$ using MG. Figure 1 compares XRD patterns of $\mathrm{Fe}-\mathrm{Si} / \mathrm{Si}$ composite powders prepared by MG for 10-30 hours. In each composite powder, $\mathrm{FeSi}_{2}$ and $\mathrm{Si}$ peaks were observed. On the other hand, the peak intensity of FeSi was decreased with increasing MG time, and the peak disappeared when MG time reached 20 hours. This indicates that a phase transformation from $\mathrm{FeSi}$ to $\mathrm{FeSi}_{2}$ took place by $\mathrm{MG}$ with the existence of excess $\mathrm{Si}$. These results suggest that the phase transformation to $\mathrm{FeSi}_{2}$ almost completed in case of MG 30 hours (Fig.S1), and that $\mathrm{FeSi}_{2}$ and $\mathrm{Si}$ phases uniformly intermixed in $\mathrm{Fe}-\mathrm{Si} / \mathrm{Si}$ composites. The crystalline size of $\mathrm{FeSi} 2$ was estimated to be about 14 nm by using Scherrer equation.

Figure 2 shows potential profiles at the first cycle for electrodes of $\mathrm{Fe}-\mathrm{Si} / \mathrm{Si}$ composites prepared by MG for 30 hours. The weight ratios of $\mathrm{Fe}-\mathrm{Si} / \mathrm{Si}$ were 30/70, 50/50, and 70/30 wt.\%. In the all electrodes, we observed potential plateaus in the charge (lithiation) reaction at $0.1-0.3 \mathrm{~V}$ vs. $\mathrm{Li} / \mathrm{Li}^{+}$and in the discharge (delithiation) reaction at $0.3-0.5 \mathrm{~V}$ vs. $\mathrm{Li} / \mathrm{Li}^{+}$, indicating alloying and dealloying reactions of Li-Si.

Figure 3 represents cycling performances of the $\mathrm{Fe}-\mathrm{Si} / \mathrm{Si}$ composite electrodes as compared with those of electrodes using $\mathrm{Si}$ alone and $\mathrm{Fe}-\mathrm{Si}$ alone. The discharge capacity of the $\mathrm{Si}$ electrode rapidly decreased with increasing the cycle number. This poor cyclability originates in properties of Si itself: low electronic conductivity, slow kinetics of Li-ion diffusion, and significant volume changes during Li-insertion and Li-extraction. In particular, the volume changes cause pulverization and loss of electrical contact for active material layer, resulting in the significant capacity fading. On the other hand, the capacity fading was suppressed for the $\mathrm{Fe}-\mathrm{Si} / \mathrm{Si}$ composite electrodes. After 30-50 cycles, the capacity of the composite electrodes exceeded that of the Si electrode. This result demonstrated that compounding 
$\mathrm{Fe}-\mathrm{Si}$ and $\mathrm{Si}$ is effective for improving performance of Si-based anode. It is easily suggested that $\mathrm{FeSi}_{2}$ phase in the composite can improve electrical conductivity and can relax the stress from Si. With increasing the amount of $\mathrm{Fe}-\mathrm{Si}$ in the composite, the cyclability was much improved though the initial capacity was reduced owing to lower amount of elemental Si in it.

To discuss the effect of MG treatment on the good cyclability, we focused on the time of MG treatment. Figure 4 presents relationship between cycle number and retention of initial capacity for the $\mathrm{Fe}-\mathrm{Si} / \mathrm{Si}$ electrodes with the ratio of 70/30 wt.\%, and dependence of MG time on the retention. In case of MG for 10 hours, the electrode showed a drastic retention decay by the 60th cycle and a very low retention of $7 \%$ at the 100th cycle. In contrast, when MG time was 20 hours or more, the electrodes exhibited good retentions higher than $60 \%$ for 100 cycles. We considered that this improved retention should be correlated with the phase transformation from FeSi to $\mathrm{FeSi}_{2}$ by MG.

As we mentioned in the introduction section, active material combining with $\mathrm{Si}$ in composite electrode is required to have four kinds of important properties: (i) mechanical properties suitable for relaxation of the stress from $\mathrm{Si}$, (ii) high electronic conductivity, (iii) moderate reactivity with $\mathrm{Li}^{+}$, and (iv) high thermodynamic stability. To make clear difference in these properties between $\mathrm{FeSi}$ and $\mathrm{FeSi}_{2}$, we separately prepared single phase $\mathrm{FeSi}$ and $\mathrm{FeSi}$ 2 powders by a mechanical alloying method $[11,15,19]$.

By a uniaxial compression test using a dynamic ultra-micro hardness tester, we evaluated a reference breaking strength (pressure required for $10 \%$ deformation) [15] for $\mathrm{FeSi}$ and $\mathrm{FeSi} 2$ powders. The breaking strengths of $\mathrm{FeSi}$ and $\mathrm{FeSi} 2$ were $229 \pm 21$ and $213 \pm 44 \mathrm{MPa}$, which were much lower than the value of $409 \pm 68 \mathrm{MPa}$ obtained for $\mathrm{Si}$. This result revealed that both silicides have a favorable mechanical property to relax the stress from $\mathrm{Si}$. No remarkable difference in the mechanical property was observed between $\mathrm{FeSi}$ and $\mathrm{FeSi}_{2}$. An electrical conductivity was studied under a uniaxial pressure for active material powder by using our measurement system [15]. The resistivity of both silicides was $2.6 \times 10^{1} \Omega$ $\mathrm{cm}$, which was about 100 times lower than that of $6.0 \times 10^{3} \Omega \mathrm{cm}$ in case of Si. It was found that FeSi and 
$\mathrm{FeSi}_{2}$ equally improve the electrical conductivity of the composite electrodes. As for thermodynamic stability, Acker et al. have reported that the standard enthalpies of formation of $\mathrm{FeSi}$ and $\mathrm{FeSi} 2$ were -74 and $-79 \mathrm{~kJ} \mathrm{~mol}^{-1}$ [30]. Thus, FeSi has as good a thermodynamic stability as $\mathrm{FeSi}_{2}$ does. There was no significant difference in the three properties, thereby indicating that an electrochemical reactivity of silicides with $\mathrm{Li}^{+}$should be different.

Figure 5 shows Li-insertion/extraction properties of thick-film electrodes using $\mathrm{FeSi}$ and $\mathrm{FeSi}_{2}$ prepared by the mechanical alloying method. In each electrode, gentle potential shoulders were observed in the initial charge-discharge curves (Fig.5(a)). We consider that these silicides reversibly store Li ions at interstitial sites in their crystal lattice as $\mathrm{Mg}_{2} \mathrm{Ge}$ does [31] though detailed reaction mechanism is still unclear. Both electrodes showed very stable cyclability for 300 cycles. The discharge capacities of the $\mathrm{FeSi}_{2}$ electrode were three times larger than those of the FeSi electrode. As for metal silicide-based composite electrodes, it is suggested that a discharge capacity of about several ten $\mathrm{mA} \mathrm{h}^{-1}$ for silicide electrodes is favorable for improving cyclability of composite electrodes though it depends on the kind of active materials and conditions of charge-discharge tests. In a typical condition of our experiments, when electrodes of metal silicide alone showed reversible capacities of about several ten $\mathrm{mA} \mathrm{h} \mathrm{g}{ }^{-1}$, silicide/Si composite electrodes exhibited better cycling performances [11,15,25]. In contrast, a $\mathrm{NiSi} 2$ electrode showed higher initial capacity than $100 \mathrm{~mA} \mathrm{~h} \mathrm{~g}^{-1}$, and thus poor cycle stability was obtained for a $\mathrm{NiSi} / \mathrm{Si}$ composite electrode because the higher reactivity of $\mathrm{NiSi}_{2}$ with $\mathrm{Li}$ leads to its large volume change and disintegration of the composite electrode [24].

Figures 6(a) and 6(b) illustrate migration pathway between the most stable interstitial sites for Li in the structures of (a) tetragonal $\mathrm{FeSi}_{2}$ and (b) cubic FeSi. The figures were created using VESTA package by K. Momma and F. Izumi [32]. The migrations in $\mathrm{FeSi}_{2}$ and $\mathrm{FeSi}$ were calculated along [100] and [110] directions in which $\mathrm{Li}$ has the longest interatomic distances to nearest neighbor atoms of Si and Fe. In case of $\mathrm{FeSi}$, we calculated the formation energies in curved pathway with consideration for asymmetry of atomic configuration. As we expected, $\mathrm{FeSi}_{2}$ exhibited less energy barrier for Li migration 
in the pathway than FeSi (Fig.6(c)) though Li concentration in the cell of $\mathrm{Li}_{0.17} \mathrm{FeSi}_{2}$ is higher than that of $\mathrm{Li}_{0.06} \mathrm{FeSi}$. This calculation results indicate that $\mathrm{FeSi}_{2}$ has a more favorable structure for Li migration than FeSi. Taking account of the larger reversible capacities of the FeSi2 electrode as shown in Fig.5(b), FeSi2 phase has an advantage not only in smooth Li-ion diffusion but also in the quantity of Li-insertion/extraction. Therefore, we consider that the electrode of $\mathrm{Fe}-\mathrm{Si} / \mathrm{Si}$ composite, in which $\mathrm{FeSi}$ transformed to $\mathrm{FeSi}_{2}$ by MG, showed the good cyclability.

\section{Conclusions}

We prepared the $\mathrm{Fe}-\mathrm{Si} / \mathrm{Si}$ composite by using $\mathrm{MG}$ for elemental $\mathrm{Si}$ and ferrosilicon, which is industrially available and less expensive material, and investigated the influence of MG on the anode performance of the composites. With increasing the MG time, the phase transformation from FeSi to $\mathrm{FeSi}_{2}$ took place more significantly, and the composite electrodes exhibited higher capacity retention for 100 cycles. As a result of measurements for the mechanical properties and the electronic conductivity, there was no remarkable difference in these properties between $\mathrm{FeSi}$ and $\mathrm{FeSi}_{2}$. On the other hand, the FeSi2 exhibited about three times larger capacities in comparison with the FeSi electrode. In addition, a result of our first principle calculation indicates that $\mathrm{Li}$ ion can diffuse more easily in $\mathrm{FeSi}_{2}$ lattice than FeSi lattice. We consider that the better cyclability of the composite electrodes was attributed to the moderate reactivity of $\mathrm{FeSi}_{2}$ with $\mathrm{Li}$ and the smooth $\mathrm{Li}$-ion diffusion in it.

\section{Acknowledgments}

This work has been partially supported by Japan Society for the Promotion of Science (JSPS) KAKENHI, Grant-in-Aid for Exploratory Research (Grant Number 25620195). This work was supported in part by the Li-EAD program of the New Energy and Industrial Technology Development Organization (NEDO) of Japan. 


\section{References}

[1] T. D. Hatchard and J. R. Dahn, J. Electrochem. Soc., 151 (2004) A838.

[2] M. N. Obrovac and L. Christensen, Electrochem. Solid-State Lett., 7 (2004) A93.

[3] M. N. Obrovac and L. J. Krause, J. Electrochem. Soc., 154 (2007) A103.

[4] C. K. Chan, R. Ruffo, S. S. Hong, R. A. Huggins, Y. Cui, J. Power Sources, 189 (2009) 34.

[5] S. Misra, N. Liu, J. Nelson, S. S. Hong, Y. Cui, M. F. Toney, ACS Nano, 6 (2012) 5465.

[6] H. Sakaguchi, H. Honda, Y. Akasaka, T. Esaka, J. Power Sources, 119-121 (2003) 50.

[7] Y. Nagao, H. Sakaguchi, H. Honda, T. Fukunaga, and T. Esaka, J. Electrochem. Soc., 151 (10) (2004) A1572.

[8] H. Sakaguchi, Y. Nagao, T. Esaka, Electrochemistry, 74 (2006) 463.

[9] H. Sakaguchi, T. Toda, Y. Nagao, T. Esaka, Electrochem. Solid-State Lett., 10 (2007) J146.

[10] T. Iida, T. Hirono, N. Shibamura, H. Sakaguchi, Electrochemistry, 76 (2008) 644.

[11] H. Sakaguchi, T. Iida, M. Itoh, N. Shibamura, T. Hirono, IOP Conf. Series: Mater. Sci. Eng., 1 (2009) 012030.

[12] H. Usui, Y. Kashiwa, T. Iida, H. Sakaguchi, J. Power Sources, 195 (2010) 3649.

[13] H. Usui, H. Nishinami, T. Iida, H. Sakaguchi, Electrochemistry, 78 (2010) 329.

[14] H. Usui, M. Shibata, K. Nakai, H. Sakaguchi, J. Power Sources, 196 (2011) 2143.

[15] H. Usui, K. Meabara, K. Nakai, H. Sakaguchi, Int. J. Electrochem. Sci., 6 (2011) 2246.

[16] H. Usui, N. Uchida, H. Sakaguchi, J. Power Sources, 196 (2011) 10244.

[17] H. Usui, T. Kono, H. Sakaguchi, Int. J. Electrochem. Sci., 7 (2012) 4322. 
[18] H. Usui, N. Uchida, H. Sakaguchi, Electrochemistry, 80 (2012) 737.

[19] H. Usui, M. Shimizu, H. Sakaguchi, J. Power Sources, 235 (2013) 29.

[20] H. Usui, K. Wasada, M. Shimizu, H. Sakaguchi, Electrochim. Acta, 111 (2013) 575.

[21] H. Usui, Y. Yamamoto, K. Yoshiyama, T. Itoh, and H. Sakaguchi, J. Power Sources, 196 (2011) 3911.

[22] H. Usui, T. Masuda, H. Sakaguchi, Chem. Lett., 41 (2012) 521.

[23] H. Usui, Y. Kiri, H. Sakaguchi, Thin Solid Films, 520 (2012) 7006.

[24] H. Usui, T. Yoneda, M. Ono, H. Sakaguchi, Abstract \#1383, 220th ECS Meeting and Electrochemical Energy Summit, Boston, MA (2011).

[25] H. Nishino, H. Usui, M. Kusatsu, T. Murota, H. Sakaguchi, Mater. Lett., 130 (2014) 61.

[26] Y. Chen, J. Qian, Y. Cao, H. Yang, X. Ai, ACS Appl. Mater. Interfaces, 4 (2012) 3753.

[27] J.-A. Choi, D.-W. Kim, Y.-S. Bae, S.-W. Song, S.-H. Hong, S.-M. Lee, Electrochim. Acta, 56 (2011) 9818 .

[28] G. Kresse, J. Hafner, Phys. Rev. B, 47 (1993) RC558.

[29] K. Nakada and A. Ishii, Solid State Commun., 151 (2011) 13.

[30] J. Acker, K. Bohmhammel, G. J. K. van den Berg, J. C. van Miltenburg, Ch. Kloc, J. Chem. Thermodynamics, 31 (1999) 1523.

[31] H. Sakaguchi, H. Honda, T. Esaka, J. Power Sources, 81-82 (1999) 229.

[32] K. Momma and F. Izumi, J. Appl. Crystallogr., 44 (2011) 1272. 


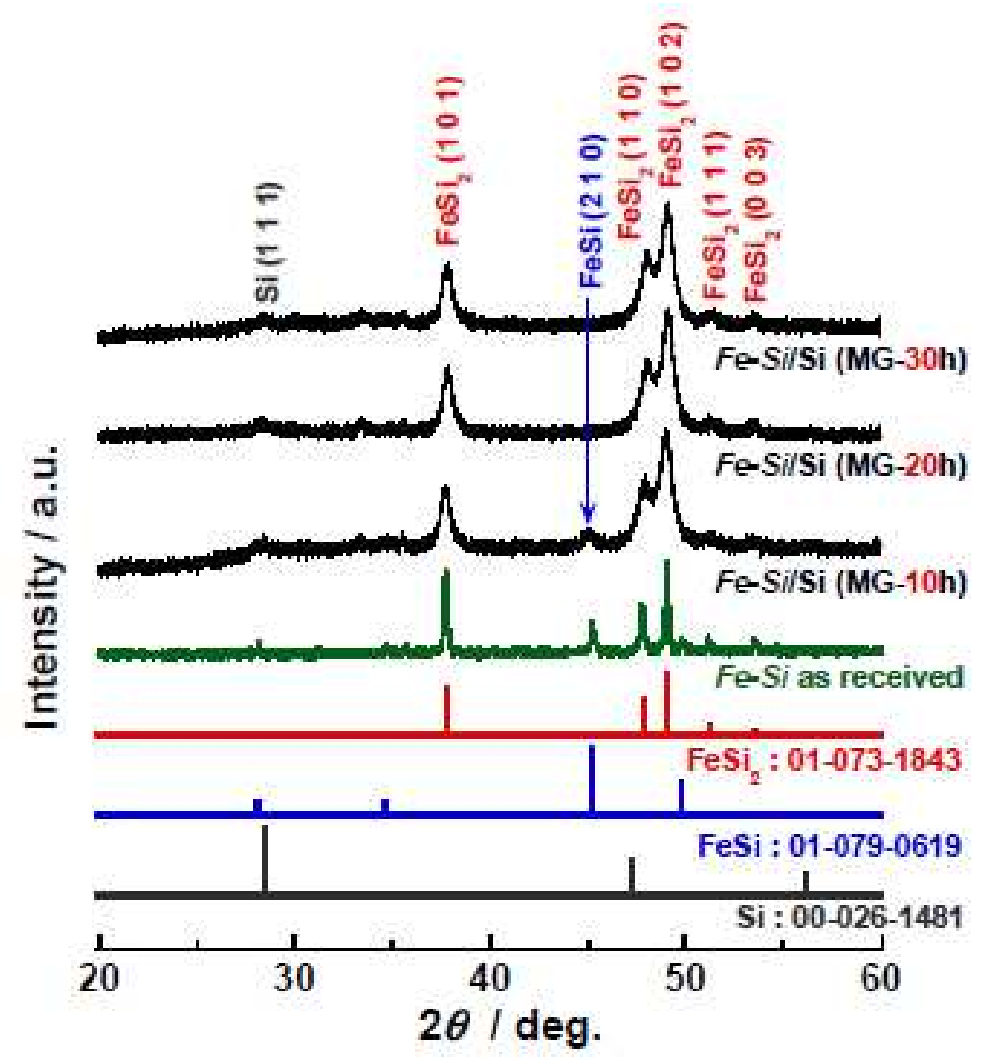

Figure 1. XRD patterns of $\mathrm{Fe}-\mathrm{Si} / \mathrm{Si}$ composite powders prepared by MG with different grinding times. 


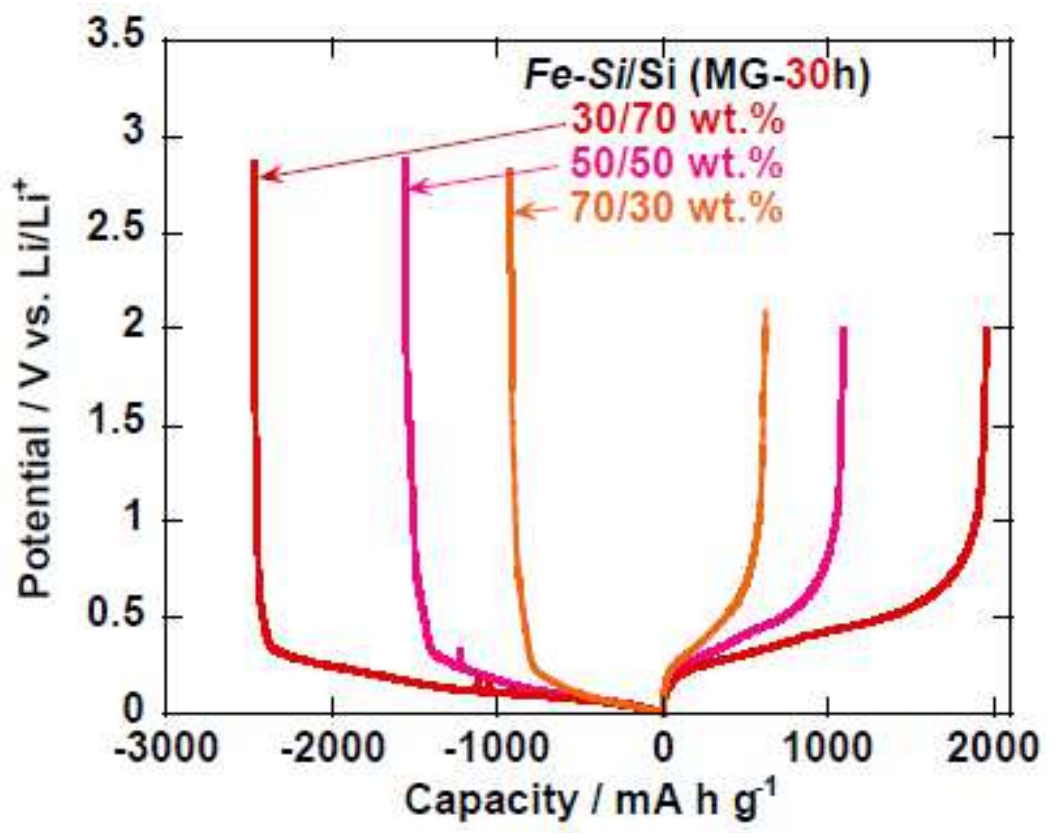

Figure 2. Initial charge-discharge curves of thick-film electrodes using $\mathrm{Fe}-\mathrm{Si} / \mathrm{Si}$ composites prepared by MG for 30 hours. The weight ratios of $\mathrm{Fe}-\mathrm{Si} / \mathrm{Si}$ were 30/70, 50/50, and 70/30 wt.\%. 


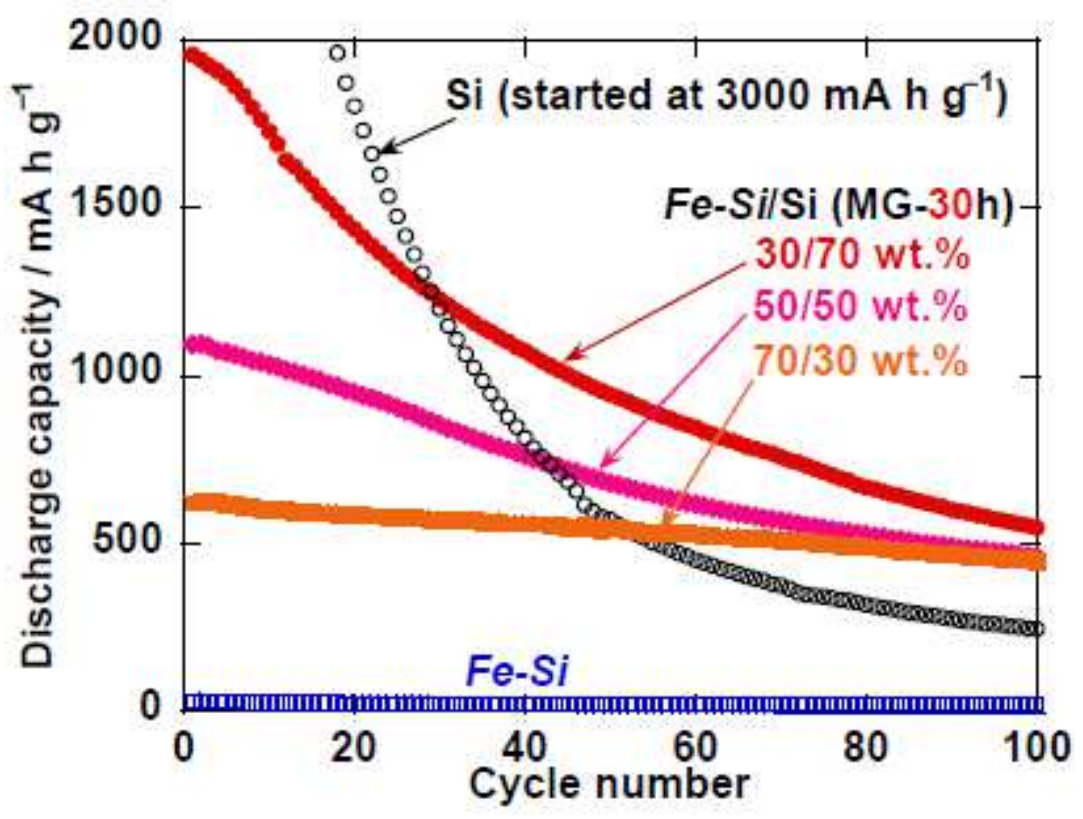

Figure 3. Charge-discharge cycling performances of the $\mathrm{Fe}-\mathrm{Si} / \mathrm{Si}$ composite electrodes. For comparison, this figure shows results for electrodes of $\mathrm{Si}$ alone and $\mathrm{Fe}-\mathrm{Si}$ alone. 


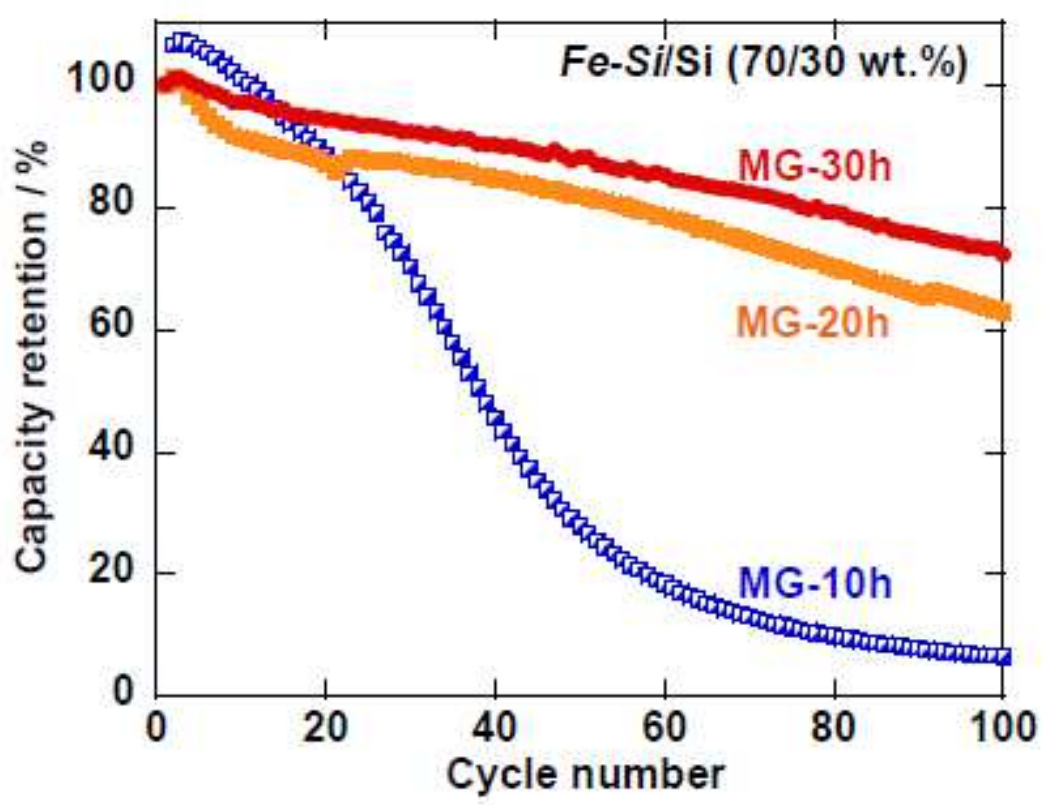

Figure 4. Effect of MG time on capacity retention of $\mathrm{Fe}-\mathrm{Si} / \mathrm{Si}$ composite electrodes with weight ratio of 70/30 wt.\%. In cases of MG times of 10, 20, and 30 hours, the electrodes showed initial capacities of 750, 600, and $620 \mathrm{~mA} \mathrm{~h} \mathrm{~g}^{-1}$. 

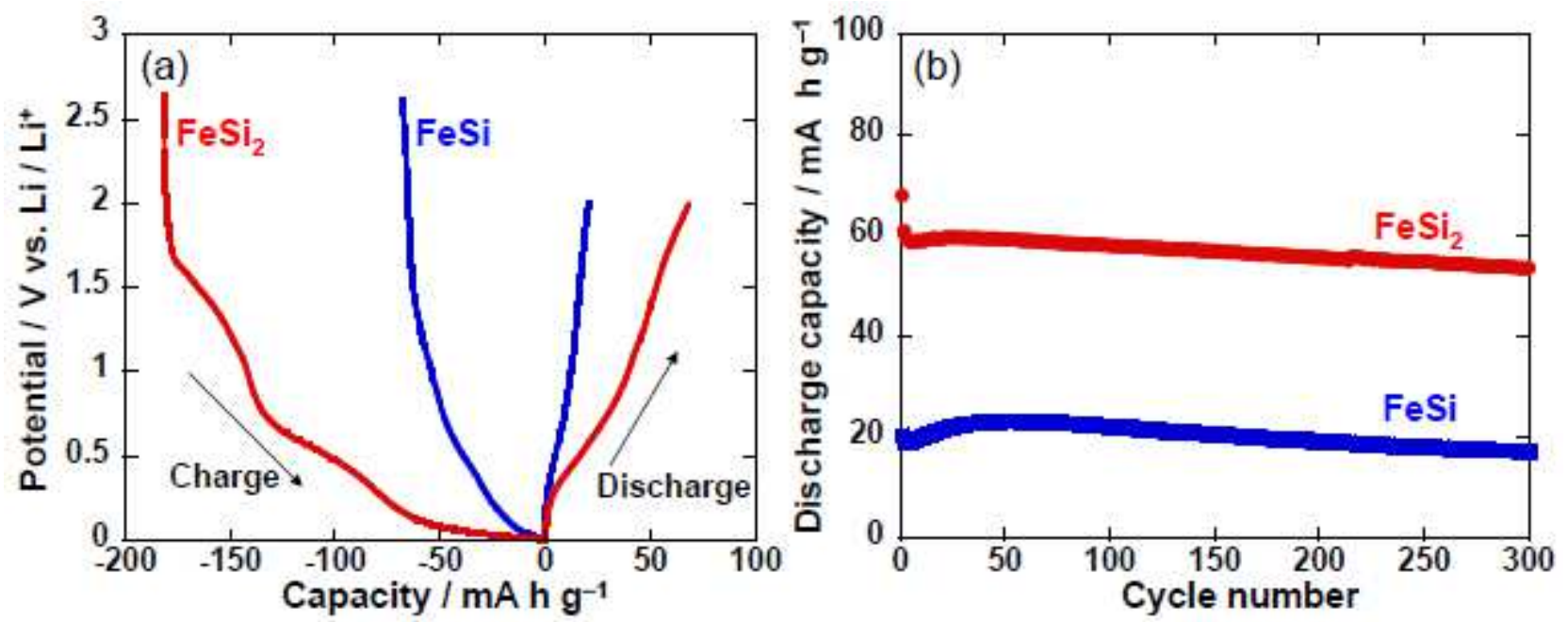

Figure 5. (a) Charge-discharge curves and (b) cycle stability for electrode of $\mathrm{FeSi}_{2}$ alone prepared by mechanical alloying method. For comparison, anode properties of FeSi electrode were also shown in the figure. 

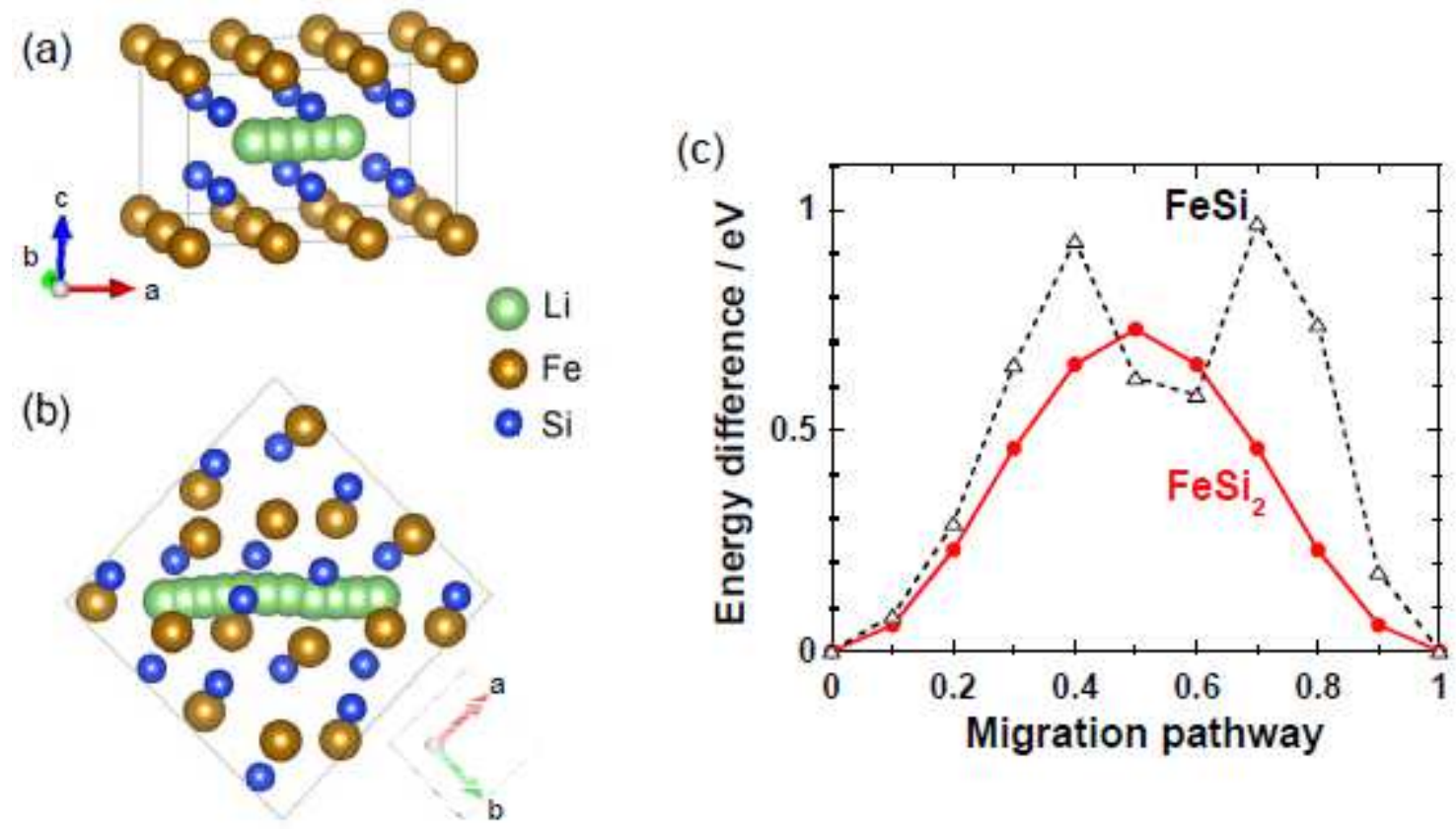

Figure 6. Migration pathway between the most stable interstitial sites for Li in crystal structures of (a) $\mathrm{FeSi}_{2}$ and (b) FeSi. The figures were created using VESTA package [32]. (c) Change in formation energies of $\mathrm{Li}_{x} \mathrm{FeSi}_{2}$ when Li migrates between adjacent stable sites. The formation energy at the most stable site of $\mathrm{Li}$ was set to be 0 . 


\section{Figure captions}

Figure 1. XRD patterns of $\mathrm{Fe}-\mathrm{Si} / \mathrm{Si}$ composite powders prepared by MG with different grinding times.

Figure 2. Initial charge-discharge curves of thick-film electrodes using $\mathrm{Fe}-\mathrm{Si} / \mathrm{Si}$ composites prepared by MG for 30 hours. The weight ratios of $\mathrm{Fe}-\mathrm{Si} / \mathrm{Si}$ were 30/70, 50/50, and 70/30 wt.\%.

Figure 3. Charge-discharge cycling performances of the $\mathrm{Fe}-\mathrm{Si} / \mathrm{Si}$ composite electrodes. For comparison, this figure shows results for electrodes of $\mathrm{Si}$ alone and $\mathrm{Fe}-\mathrm{Si}$ alone.

Figure 4. Effect of MG time on capacity retention of $\mathrm{Fe}-\mathrm{Si} / \mathrm{Si}$ composite electrodes with weight ratio of 70/30 wt.\%. In cases of MG times of 10, 20, and 30 hours, the electrodes showed initial capacities of 750, 600 , and $620 \mathrm{~mA} \mathrm{~h} \mathrm{~g}^{-1}$.

Figure 5. (a) Charge-discharge curves and (b) cycle stability for electrode of FeSi2 alone prepared by mechanical alloying method. For comparison, anode properties of FeSi electrode were also shown in the figure.

Figure 6. Migration pathway between the most stable interstitial sites for Li in crystal structures of (a) $\mathrm{FeSi}_{2}$ and (b) FeSi. The figures were created using VESTA package [32]. (c) Change in formation energies of $\mathrm{Li}_{x} \mathrm{FeSi}_{2}$ when Li migrates between adjacent stable sites. The formation energy at the most stable site of Li was set to be 0 . 